\title{
IMPACT OF ADVERTISING ALCOHOL AND TABACCO ON THE BEHAVIOR OF YOUNG GENERATION
}

\author{
L. Spasova*, Zh. Gundasheva \\ Department of Social Sciences and Business Language Training, \\ Trakia University, Stara Zagora, Bulgaria
}

\begin{abstract}
The author examines the role of advertising alcohol and tobacco and notes the characteristics of such publicity campaigns. Issues associated with current efforts to further restrict or ban alcoholic beverage and tobacco advertising are explored. Different restrictions related to marketing, advertising and promotions suggest different requirements and prohibition practices. However, the problem is that modern advertising practices have become widely accessible, because they allow fast business exposure of such products.

The aim of this research report is to show what the prohibitions and restrictions on advertising of alcohol and tobacco are and why society accepts them. The following tasks are solved in order to achieve this goal:

- Research on alcohol and tobacco producers;

- Comment on proposals for banning the advertising of cigarettes and alcohol;

- Research on advertising of alcohol and cigarettes to children;

- Analysis of alcohol and tobacco advertising restrictions: are they constitutional.

The methods used for achieving this goal and resolving the tasks are: analysis of proposals to ban advertising, analysis of different types of target groups, situation analysis, comprehensive approach.
\end{abstract}

Keywords: restrictions, global promotions, alcohol and tobacco.

\section{INTRODUCTION}

Advertising alcohol and tobacco is often a sensitive topic because of the side effects these products have on the human body. The two leading producers of tobacco and alcohol in the USA are responsible for over 100, 000 alcoholrelated deaths and over 400, 000 tobaccorelated deaths annually in the USA. Alcohol and tobacco products have a lot in common: they sustain massive economic networks combining the interests of producing corporations in different industries, publishers, advertising agencies, broadcasters, farmers, labor unions and trade associations, etc.. They create a marketing climate with unique legal and ethical systems targeting underage users. Alcohol and tobacco products are also heavily promoted by slick advertisements that associate their use with images of pleasurable and satisfactory life. People think that they are

\footnotetext{
*Correspondence to: Lyubomira Venkova Spasova, Department of Social Sciences and Business Language Training, Faculty of Economics, Trakia University, Stara Zagora, Bulgaria,e-mail: liubomira1975@abv.bg; GSM:088613829.
}

"the right" products and their use is associated with initiation to adulthood. Moreover, both have been the target of campaigns to impose restrictions on their marketing, especially by curbing all or some kinds of advertising.

\section{THEORETICAL FRAMEWORK OF THE STUDY}

While many laws and regulations determine what advertisers can and can not do, not every issue is covered by a rule. Marketers and advertisers must often make decisions regarding appropriate and responsible actions based on ethical considerations rather than on what is legal or within industry guidelines. Ethics are moral principles and values that govern the actions and decisions of an individual or group. (3) But we understand that a particular action may be within the law and still not be ethical. A good example of this involves target marketing, because no laws or governmental restrictions can ban alcohol and tobacco companies from advertising and promoting their products. However, when we consider the high levels of lung cancer and alcohol- and smoking-related illnesses among 
the disadvantaged populations, many people would consider this an unethical business practice.

We know that advertising is a very powerful force, and this research would not be complete without a look at the criticisms regarding its social and economic effects as well as some defenses against these charges. The author considers the various criticisms of advertising from an ethical and social perspective and then appraises the economic effects of advertisings. Ethical issues must be considered in integrated marketing communications decisions. Throughout this research we have presented a number of ethical perspectives to show how various aspects of advertising involve ethical features. The role of advertising in societies is very controversial and has sometimes resulted in attempts to restrict or ban advertising and other form of promotion to certain groups or for certain products like alcohol and tobacco. Young people are one such group because statistics in America show that about $90 \%$ of smokers start before the age of 21 and $82 \%$ before age 18. Brand loyalty for cigarettes is higher than for any other major consumer product. About half of all smokers never change brands. (11) Therefore, attracting beginning or young smokers pays big dividends.

A study by Columbia University's Center on addiction and substance abuse a few years ago concluded that America's colleges are witnessing a major increase in binge drinking, particularly among young women, and as many as one in three students abuses alcohol. The study advocated a ban on alcohol-related advertisings. In 1996 legislation was proposed to Congress that would stringently restrict alcohol advertising. Among the proposed restrictions is banning sponsorship or support of any athletic, musical, cultural or social event at colleges by any alcoholic beverage company and limiting college newspaper advertising to no more than price and product information. (12)

Decisions to ban the advertisings of alcohol or tobacco always involve very complex economic, social and ethical considerations as well as very issues. Companies recognize the need to reduce alcohol abuse and drunk driving, particularly among young people. The companies have produced a number of advertisings designed to address this problem and the new advertisings promote responsible behavior among adults of legal drinking age and are intended for that audience.

\section{ADVERTISING ALCOHOLIC BEVERAGES AND TOBACCO PRODUCTS}

\section{- $\quad$ Advertising alcoholic beverages}

In the 1990s and 2000 alcoholic beverage advertising was relatively unsophisticated and most beer advertising, for instance, the Hamm's beer animations of bears at play, was low-key and simple. Advertising distilled spirits and wine was similarly unsophisticated. But after 1990 all this changed with the injection of powerful advertising methods from the world of cigarette marketing. We can present the different percent of alcohol use in the next table:

Table 1. Percent of American adults that drink.

\begin{tabular}{|l|l|l|l|}
\hline Year & Percent of American adults that drink & Percent of men & Percent of women \\
\hline 1990 & $65 \%$ & $70 \%$ & $61 \%$ \\
\hline 1995 & $67 \%$ & $75 \%$ & $63 \%$ \\
\hline 2000 & $69 \%$ & $77 \%$ & $64 \%$ \\
\hline 2005 & $69 \%$ & $79 \%$ & $66 \%$ \\
\hline
\end{tabular}

Of Americans who drink, $47 \%$ prefer beer, 29 $\%$ wine, and $18 \%$ hard liquor. (Figures in this paragraph are from Leslie McAneny, Alcohol in America: Number of drinkers holding steady, but drinking less, The Gallup poll monthly, June 2005, pp.15, and 18.)

The percentage of drinkers has not diminished over the years and people who drink today drink less and the alcoholic beverage industry is in what one analyst calls "a controlled slide". A trend toward more moderate drinking is the result of the aging of the babyboom generation and of new concerns about the health effects of heavy drinking. In this mature and stagnant market there is fierce competition for market share in all three major segments - beer, wine and distilled spirits. A critical weapon in this competition is advertising and criticism often focuses on the actions of specific advertisers. For example, groups like the National Organization for Women and Women against pornography have 
been critical of advertisers such as Calvin Klein for promoting sexual permissiveness and objectifying women in their advertising. As we see later a number of advertisers have been criticized for running commercials that are insensitive to certain segments of societies.

Alcoholic beverages can be harmful. It is estimated that there are 105, 000 alcoholrelated deaths annually which impose $\$ 98,6$ billion in economic losses. Not only is alcohol a risk factor for disease, it is also implicated in accidents, crimes, and antisocial behavior. At least 11 million Americans are alcoholics. (Center for Science in the public interest, Comments on nutrition and your health: Dietary guidelines for Americans, Washington, D.C.: CSPI. January 9, 1995, p.7)

A recent survey shows that $21 \%$ of Americans want to ban alcohol completely. This group supports a strong anti-alcohol movement, which some call a neo-prohibitionist movement. In recent years the movement has gained strength because of outrage about drunk-driving deaths and growing knowledge of medical problems such as fetal alcohol syndrome. It is energized by activists in dozens of church, health and citizens' groups. Its greatest success to date has been in getting all states to rise the legal drinking age to 21 . In addition, the movement wants to ban or limit alcoholic beverage advertising should be restricted. First of all the argue that advertising and promotion increase consumption. Advertising is designed to attract new drinkers and promote additional drinking. Secondly, ubiquitous commercials influence children and teenagers to start drinking, feature sports stars or celebrities admired by those under age 21 , and use young-looking models or actors. Researchers report that fifth- and sixth-grade children who can describe specific alcohol commercials have more positive attitudes toward drinking than less knowledgeable children. (9) And last but not least, advertising agencies promote alcohol with images of hang gliding, mountain climbing, and ski-diving activities in which drinking would be dangerous. These advertisings attempt to play on the viewers' emotional needs for popularity, success, achievement, and romance and associate alcohol with fulfillment of these needs.

\section{- $\quad$ Advertising tobacco products}

The next very famous products that are advertised are the tobacco products. If we follow the process of development of some promotional products such as cigarettes and alcohol, we will find out that in the early 20th century prominent representatives working in advertising as D. Ogilvie, R. Reeves, K. Hopkins including PR specialists like E. Bernays, Lee and John Hill and others seek to get mankind to accept products that are not only useful, but they are in total contradiction with a healthy lifestyle. We considered products such as cigarettes, alcohol and coffee. (11) The achievements are unique; we can only recognize results in our present. The use of psychoanalysis as a basis for advertising and establishing a series of scientific papers on the benefits of the products is common practice today, but it is not always a guarantee for conducting a successful campaign.

Today about 50 million Americans or about 25 $\%$ of the adult population, smoke cigarettes, and another 12 million use other tobacco products. In addition to these adults, an estimated 7 to $13 \%$ of children and adolescents under the age of 18 smoke and 12 $\%$ of males ages 12 to 17 use smokeless tobacco. (Figures in this paragraph are from U. S. Food and Drug Administration, Federal Register, August 11, 1995, pp.41-45.) In recent years the number of adult smokers has held steady and the number of underage smokers has slowly increased. Overall, smokers are smoking less and cigarette consumption in the domestic market has declined by an average of 2 to $3 \%$ each year since the mid-1980s.

Each year over 400, 000 Americans die from smoking-related diseases. About 1.4 million smokers quit. This means that new smokers must be recruited to fill the ranks that are constantly depleted, and each year the tobacco industry spends billions of dollars to advertise and promote its products. About 3,000 persons take up smoking every day in the US; almost all of them are under age 18 .

\section{BASIC RESEARCH HYPOTHESIS}

Every year we are witnesses of these processes, but we consider the results without taking the necessary measures. The question is: Is the impact of advertising the reason for the use of these products or not?

It was found that advertising influences associative, impulsive-conducive and if there is any manipulation of the minds of the audience, it is sympathetic as opposed to propaganda and public relations. (9) Furthermore, advertising is a combination of different creative approaches for offering the necessary and useful. The impact is not direct, in relation to induced primary and secondary target associations. 
Developing an advertising strategy coincides in time and place with the development of other relevant strategies, where the objects of advertising can be presented differently in terms of approaches, but similarly in regard to targets, i. e. the intended effect on the minds of the audience. The impact of advertising today does not lie in introducing new, unknown fetishes, because consumers are aware of the products and their appeal, , but in using aesthetic values and playing on clients' expectations to create a value for the product sold. It should not be aggressive, shocking the mind with advertising techniques but selectively to aim at the perception and senses of the use of the products as alcohol and cigarettes.

Assuming that advertising does not exist or does not send signals to the younger generation, the question is: How long will previous generations pass on their bitter experience with cigarettes and alcohol and thus affect the young generations?

A general counselor to tobacco advertising businesses says: "We understand that when advertising is run it is going to be seen by some people who are under 21 years of age, whether it is a billboard, in a magazine, or on TV. That does not mean we target the group that is less than 21". This is right, but the results are other for us.

Beer companies and TV executives insist that it does not make sense to negatively evaluate beer advertisings on a single audience for a one-week period. Miller officials noted that more than $75 \%$ of the broadcast audience reached by the programming it buys is over 21 . The issue of whether brewers are targeting teens comes at a time when a great deal of attention is being focused on the problem of underage drinking. The actions of beer, wine and liquor marketers are being closely scrutinized in Washington (2005) in the wake of the distilled spirits industry's decision to reverse a long-standing ban on $\mathrm{TV}$ and radio advertising.

And now we can look at a table which demonstrates the influence of alcohol advertisings and the teenagers:

Table 2. Who's watching the different programs and alcohol ads - Highlights of a week's worth of beer advertising in America. (2005)

\begin{tabular}{|l|l|l|l|}
\hline Advertiser & Show (Network) & Date (Time) & $\begin{array}{l}\text { Percent Viewers } \\
\text { under 21 }\end{array}$ \\
\hline Coors Light & Hit List (BET) & Sept. 2 (8-10 P.M.) & $51 \%$ \\
\hline Molson & Singled Out (MTV) & Sept. 2 (7 P.M.) & $52 \%$ \\
\hline Molson Ice & $\begin{array}{l}\text { Beavis and Butt-head } \\
\text { (MTV) }\end{array}$ & Sept. 2 (11:30 P.M.) & $48 \%$ \\
\hline Foster's & Singled Out (MTV) & Sept. 2 (11 P.M.) & $46 \%$ \\
\hline Molson & Real World (MTV) & Sept. 3 (8:30 P.M.) & $45 \%$ \\
\hline Foster's & Melrose Place (E!) & Sept. 2 (7-8 P.M.) & $41 \%$ \\
\hline Miller & Unreal (BET) & Sept. 5 (8-10 P.M.) & $65 \%$ \\
\hline Schlitz & Your MTV (MTV) & Sept. 5 (10 P.M.) & $50 \%$ \\
\hline Molson & $\begin{array}{l}\text { Beavis and Butt-head } \\
\text { (MTV) }\end{array}$ & Sept. 6 (10:30 P.M.) & $69 \%$ \\
\hline Budweiser & $\begin{array}{l}\text { Video Music Awards } \\
\text { (MTV) }\end{array}$ & Sept. 7 (8:30 P.M.) & $46 \%$ \\
\hline
\end{tabular}

Sources: Competitive Media Reporting (advertising placement), Nielsen Media Research (viewer demographics) in The Wall Street Journal, January 6, 2005, p.B1.

One of the major complaints about advertising is that much of it is misleading or untruthful and deceives consumers. Attempts by industry and government to regulate and control „deceptive" advertising are discussed every day. The industry does not deny the practice of targeting younger drinkers with specific advertising themes. Market segmentation and the targeted advertising that accompanies it is standard marketing practice in many industries. When alcoholic beverage companies focus on minority communities and women, critics say that these consumers are too gullible and naïve to withstand manipulation, implying that members of these groups are not as astute as male consumers.

The difficulty to determine just what constitutes deception, along with the fact that 
advertisers have the right to use puffery and make subjective claims about their products, tends to complicate the issue. While many critics of advertising would probably agree that most advertisers are not out to deceive consumers deliberately, they are still concerned that consumers may not be receiving enough information to make an informed choice. They say advertisers usually present only information that is favorable to their position and do not always tell consumers the whole truth about a product or service. National advertisers in particular invest large sums of money to develop loyalty to, and enhance the image of, their brands. These companies are not likely to risk hard-won consumer trust and confidence by intentionally deceiving consumers. (2)

Some people believe advertising should be primarily informative in nature and should not be permitted to use puffery or embellished messages. Other people argue that advertisers have the right to present the most favorable case for their products and should not be restricted to just objective information. But the situation is very difficult with young people because they use different alcoholic and tobacco products. Tobacco marketers claim that they do not target underage smokers, but there is evidence that advertising influences initiation and brand choice in this group. Underage smokers prefer the tree most advertised brands - Marlboro (60\%), Camel $(13,3)$ and Newport $(12,7)$. (U.S. Food and Drug Administration, Regulations Restricting the Sale and Distribution of Cigarettes, p. 314) Only $3 \%$ of underage smokers preferred the Camel brand before R. J. Reynolds introduced its Joe Camel advertising campaign. Since then the number of under-18 Camel smokers has jumped to $13,3 \%$, while adult smokers have not changed preferences. (4)

\section{RESEARCH ON THE ADVERTISING OF ALCOHOL AND TOBACCO}

As a method for collecting primary data to limit alcohol advertising direct personal questionnaire is used in the form of a standardized questionnaire among respondents aged 6 to 18 years in Bulgaria. For the realization of the study two separate surveys were developed and conducted:

Research framework on the proposal to limit alcohol advertising:

- among children 6 to 12 years exposed tothe media and social networks for an average of 1 to 7 hours per day;
- among teenagers 13 to 15 exposed to the media and social networks for an average of 5 to 10 hours per day;

- among young people from 16 to 18 exposed to the media and social networks for an average of 2 to 8 hours a day.

In order to measure and evaluatee the impact of advertising on the attitudes and behavior of respondents we used contextual approach to allow examination of the problem in a broader context as a social macrosystem, such as the European Union. Not only the contribution of the various regulatory authorities was examined for the implementation of relevant performance, but also its interaction with organizational and external environment within which the relevant decisions are made.

The research tool to assess the impact of advertising on the behavior of respondents consists of two blocks. The first block includes statements by respondents measured at Lickert 5-point scale (from 1 - "ignore ads for alcohol and cigarettes" to 5 - "watching with interest ads for alcohol and cigarettes'). Satisfaction in contact with relevant ads is determined by the second block of questions reflecting the change in the attitudes and behavior of adolescents. This establishes how often respondents use banned products under the impact of advertising. The assessment was carried out from option 1 - "I think that these products harm my health" to option 5 - "I like the products because they are part of our daily lives" on the following criteria: - quality of ads; - availability of products; - frequency of interaction with advertising products; competence in the use of alcohol and tobacco products. This establishes how often respondents use banned products under the influence of advertising. The research was carried out by three variables: participation of the person in making decisions; providing access to information by the media; opportunity to build habits when purchasing.

Based on the reasoning of a link between the interaction of advertising and the attitudes and behavior of the young generation the following hypotheses were defined:

H1 - absence / presence of a statistically significant relationship between advertising and the attitudes of the younger generation.

$\mathrm{H} 2$ - absence / presence of a statistically significant relationship between advertising and the behavior of the younger generation.

The excerpt is of the type " random respondents." For its formation 18 respondents were contacted who had information related to 
the problem. Selected alcohol and cigarettes commercials were located in different print and electronic media and the Internet. The questions included in the excerpt direct the young consumers to the principles of impact of advertising and how some of the content is memorized. The frequency of purchasing advertised products was determined. To establish regularities and relations between advertising and behavior of the younger respondents the analysis will draw parallels to similar studies on the same problem in the US and Belgium.

\section{EMPIRICAL RESULTS}

Six US-based studies and a Belgian one show that the volume of advertisements and media exposure increases the number of young people starting to consume alcohol and use tobacco products. (Look at the next table). These findings are similar to the impact of advertising on smoking, and are not surprising. It is difficult to study the relationship between the expenditure on commercial communications, and whether there is or there is no greater consumption of alcohol by young people. The question is: In which countries
SPASOVA L., et al.

has this been done, because some studies have found that increased expenditure on advertising is associated with increased alcohol-related harm, whereas others have not? In general, later studies have found more than one instance of the effects of commercial communications.

Also the impact that advertising can have on young people's behavior is illustrated by smoking, because the different advertisements are associated with cigarette use. Lovato found that 12000 non-smokers, who were exposed to tobacco advertising and promotion, would start to smoke, because they started to think differently about tobacco advertisings. Therefore, the impact of advertisings increases the likelihood that adolescents start to smoke.

In the USA Ellickson (2005) followed over 3000 13-15-year-olds for three years. (6) The explorer compared drinkers and non-drinkers and found that exposure to in-store beer displays predicted drinking onset for nondrinkers after 2 years, and exposure to advertising in magazines and looking at sports or music predicted frequency of drinking after 2 years.

Table 3. Impact of commercial communications and young people's behavior

\begin{tabular}{|c|c|c|c|c|}
\hline Study & Country & $\begin{array}{l}\text { Age group } \\
\text { (years) }\end{array}$ & $\begin{array}{l}\text { Follow- } \\
\text { up } \\
\text { (months) }\end{array}$ & Outcome at follow-up \\
\hline $\begin{array}{l}\text { Robinson et al. } \\
\text { (1998) }\end{array}$ & USA & $14-15$ & 18 & $\begin{array}{l}\text { Each 1-hour increase in television viewing } \\
\text { associated with a } 9 \% \text { increased risk for } \\
\text { initiating drinking. }\end{array}$ \\
\hline $\begin{array}{l}\text { Wingood et al. } \\
2003\end{array}$ & USA & 14-18 & 12 & $\begin{array}{l}\text { High exposure to rap music leads to } 1.5 \\
\text { times greater likelihood to use alcohol over } \\
12 \text { month period compared with low contact } \\
\text { with a media. }\end{array}$ \\
\hline Stasy et al. (2004) & USA & $11-12$ & 12 & $\begin{array}{l}\text { Those who watched } 60 \% \text { more alcohol } \\
\text { advertisements on TV were } 44 \% \text { more } \\
\text { likely to have used beer, } 34 \% \text { more likely to } \\
\text { have ever used wine / liquor. }\end{array}$ \\
\hline $\begin{array}{l}\text { Van Den Bluck \& } \\
\text { Beullens (2005) }\end{array}$ & Belgium & $13-16$ & 12 & $\begin{array}{l}\text { Quantity of alcohol consumed while going } \\
\text { out related to over all TV viewing and their } \\
\text { music }\end{array}$ \\
\hline $\begin{array}{l}\text { Elickson et al. } \\
(2005)\end{array}$ & USA & $13-15$ & 36 & $\begin{array}{l}\text { Exposure to in-store beer displays, } \\
\text { advertising in magazines and beer } \\
\text { concession. }\end{array}$ \\
\hline Snyder et al. (2006) & USA & $15-26$ & 21 & $\begin{array}{l}\text { For every } 4 \% \text { more alcohol advertisements } \\
\text { seen on TV, radio, billboards and in } \\
\text { magazines drank } 1 \% \text { more drinks per } \\
\text { month. }\end{array}$ \\
\hline $\begin{array}{l}\text { Sargent et al. } \\
(2006)\end{array}$ & USA & $10-14$ & $12-24$ & $\begin{array}{l}\text { Significant linear and quadratic relationship } \\
\text { between movie alcohol exposure and } \\
\text { initiation of drinking, with a higher dose } \\
\text { effect relationship at lower movie alcohol } \\
\text { exposure levels compared to higher levels. }\end{array}$ \\
\hline $\begin{array}{l}\text { McClure et al. } \\
(2006)\end{array}$ & USA & $10-14$ & $12-24$ & $\begin{array}{l}\text { Owners of alcohol branded merchandise } \\
\text { had higher rates of alcohol initiation }(25 \%) \\
\text { compared with non-owners }(13,1 \%)\end{array}$ \\
\hline
\end{tabular}


The data presented in the table show that advertising of alcoholic beverages is associated with positive attitudes and beliefs of young people, and that the content of advertisings is related to expectancies about the use of alcohol amongst young people and the role of alcohol in their lives. As with the impact of advertising on smoking behavior, there are some longitudinal studies which show that the volume of advertisings and media exposure increase the likelihood of young people starting to drink, and the amount they drink on any one occasion. Therefore, according to Anderson (1) we can conclude that the rules relating to the advertising of alcoholic and tobacco products should in specific cases be approximated across Europe, and that, in particular there is a need to specify the extent to which alcohol advertising in certain categories of media and publications is allowed.

The results of these study respondents who directly interact with promotional products show that $45 \%$ of them are influenced by the advertising of alcohol and cigarettes because they change their behavior. Only $13 \%$, despite the fact that they contact the media, hardly used or never used alcohol or cigarettes. The share of active use of the products is $11.6 \%$, i. e. for these respondents are supposed to become permanent clients of manufacturers of cigarettes and alcohol.

After analyzing the responses of respondents form an average grade of general level of use under the influence of advertising media $3.45 \%$ or $1 / 6$ of respondents' frequent contact with these ads and are almost constant users of their products, they believe that this is completely normal for their age. This result is due to assessments of individual motivators that are positioned in the range of 3 to 4 , i. e. between neutral and assessment "rather enjoying active" (Table 1). (12)

At low levels of use of the advertised product was observed in the respondents from 6 to 12 , wherein there is a lack of information and satisfaction with the use of the product. Interest in the case is a one-hour increase in TV viewing and presence in social networks, leading to greater consumption: $2 \%$ for alcohol and $4 \%$ for cigarettes. This finding confirmed the discovery of Robinson and colleagues conducted in 1998 among 14-15-year-olds. (Table 3) The reason for the discrepancy between the level of importance of the problem and the level of consumption under the influence of advertising on young people can be found in the lack of filtering of advertisement which leads to urge young people to become addicted users. This effect is stronger; the more disadvantaged a socioeconomic environment. (10) Even messages and warnings included in advertising are not understood by children and can not be regarded as protective or deterrent. Fewer than five children are unable to distinguish between program and advertisements and even after that age they do not recognize its function in advertising persuasion. This skill appears only about eight years old and not at all children. It still does not mean that they can realize the bias of the messages that focus on the positive and ignoring other, more negative aspects of the product.

\section{CONCLUSION}

The results of the studies with three groups of respondents lead to the following important conclusions:

First of all, factors that in the highest degree influence the attitudes and behavior of younger generations are: leisure, family income, access to information, desire for socialization, opportunities to use the products. Accordingly, these tools are used by advertisers in combination or alone (depending on their average estimates).

Secondly, Very important measures to reduce the consumption of alcoholic beverages and tobacco are to educate the younger and more mature generation, to exercise regulation and control by governments through restrictions and prohibitions on the use of banned products, to study the attitudes and behavior of adolescents, and limit the production of alcohol and tobacco. The weighted average estimates of respondents indicate that it is advisable to have surveyed companies explore the possibilities of restricting access to their products. It was found that awareness and competence of young people about the high incidence among users of those products is important because this is where the most serious discrepancies in the assessment of the three groups of respondents are found. It is also advisory to register higher levels of use in the absence or with incomplete information.

Thirdly, communication policy in terms of credibility can be informative or manipulative. Young people can not and should not be used unconditionally as a source of income, because after a short time they become permanent customers who express and impose their opinions on what to buy. The main argument in support of this conclusion is that the impact on the audience of teenagers is favorable to the advertiser and manufacturer. 
Limitations of the performed studies and the results obtained highlight the following guidelines for future work in the study area:

- Whether the individual characteristics of personality affected the perception of the products;

- To understand the attitudes and behavior of adolescents who are exposed to the messages in advertising;

- To examine consumer behavior when buying and to look for reasons that manipulate their behavior (by individual components).

\section{REFERENCES}

1. Anderson, P., Commercial Communication and Alcohol. Utrecht: National Foundation for Alcohol Prevention, Available from: http://www.stap.nl / content / testament/ 4 report on impact, 2007.

2. Belch, G. et.all., Advertising and Promotion, Sixth Ed., London, the McGraw Hill Companies, 2003.

3. Berkoviz, E., Маркетинг, $2^{\text {nd }}$ Ed., London, Open University Press, p. 90, 1992.

4. Cappelli, P. Rethinking Employment. In Schuler, R. S. and Jackson, S. E. (eds) Strategic Human Resource Management. Oxford: Blackwell, British Journal of Industrial Relations, 33(4): pp. 282-316, 2000.

5. Center for Science in the public interest, Comments on nutrition and your health:
SPASOVA L., et al.

Dietary guidelines for Americans, Washington, D.C.: CSPI. January 9, p.7, 1995.

6. Collins, C., Ellikson, L., McCaffrey, D., \& HAMBARSOOMIANS, K., Early Adolescent Exposure to Alcohol Advertising and Its Relationship to Underage Drinking. Journal of Adolescents Health, p. 527-534, 2005.

7. Deanov, P., Psychology of Communication, $1^{\text {st }}$ Ed., Sofia, Open University Press, ISBN 954-8194-31-7, 1999.

8. DEPARTMENT OF HEALTH AND HUMAN SERVICES, Smoking and Health in America, Atlanta, Ga.: DHHS, p. 78, 1992.

9. Kaatz, R., Advertising\& Marketing Checklists, Lincolnwood, III. NTC Business Books, 1995.

10.Kotler, P., Marketing Management: Analysis, Planning, Implementation, and Control. $6^{\text {th }}$ Ed., Englewood Cliffs, N.J.: Prentice Hall, p. 776, 1998.

11. Ogilvy, D., Ogilvy on Advertising, $4^{\text {th }}$ Ed., New York: Crown Publishing, 1983.

12.Schneider, B., et.all.(2003) Which Comes First: Employee Attidudes or Organizational Finacial and Market Performance? // Journal of Applied Psychology, Vol. 5, p. 839, 2003. 